\title{
Effects of communication style and time orientation on notification systems and anti-virus software
}

\author{
Ding-Long Huang ${ }^{\mathrm{a} *}$, Pei-Luen Patrick Rau ${ }^{\mathrm{a}}, \mathrm{Hui} \mathrm{Su}^{\mathrm{b}}, \mathrm{Nan} \mathrm{Tu}^{\mathrm{a}}$ and Chen Zhao ${ }^{\mathrm{b}}$ \\ ${ }^{a}$ Department of Industrial Engineering, Tsinghua University, Beijing 100084, China; ${ }^{b}$ IBM China Research Laboratory, \\ Beijing 100094, China
}

(Received 5 February 2008; final version received 14 November 2009)

\begin{abstract}
The objectives of this study were (1) to investigate the effects of communication style (CS) and time orientation (TO) on people's perception of and proficiency in responding to notification systems and (2) to study the applications of these effects in the design of user notification in anti-virus software. Significant effects were found in the experiment; the results showed that users with a low-context CS can remember and make sense of the information provided by the notification system better than users with a high-context CS. Polychronic users perceive a lower level of interruption of the notification messages than monochronic users; polychronic users prefer rapid and accurate responses to the stimuli provided by the notification system, whereas monochronic users tend to avoid responding to the stimuli. Four sessions of focus group discussions were then carried out with users of different CS and TO, which focused on the virus attack warning provided by anti-virus software. The results should prove useful to aid designers in creating more effective and appealing ways to give notification or warnings to users.
\end{abstract}

Keywords: time orientation; communication style; notification systems; anti-virus software

\section{Objectives and significance}

While operating computers, people often want to be notified of important and emergent information, such as the arrival of new email, instant messages from friends, the arrangement of urgent tasks and warnings of virus attacks. Notification systems enable users to receive current, valuable information while performing their current activities in an efficient and effective manner (McCrickard and Chewar 2003, McCrickard et al. 2003).

The benefits of notification systems can be numerous (McCrickard and Chewar 2003), and many notification systems have been designed. However, the effects of incoming information provided by notification systems are perceived differently by different users. How well do the users comprehend the information provided by notification systems? To what extent will they avoid relocation of attention focus from their current activities? And how frequently will they react to the notifications? (McCrickard and Chewar 2003, McCrickard et al. 2003). These issues are all related to the users' individual differences. The success of a notification system hinges not only on accurately supporting attention allocation between tasks, but also on adapting the software according to individual differences, which can be attributed to race, gender, socioeconomic status, geographic locale and cultural style. This study focused on two factors:

- Monochronic/polychronic time orientation (TO): a group or category in which things are done one at a time/many at a time.

- High/low-context communication style (CS): high/low amount of stored or unspoken information in a given communication.

These two factors were first described by Hall (Hall 1983, 1987, 1990), as two dimensions of cultural differences. Culture includes knowledge, beliefs, the arts, morals, customs, and any other capabilities and habits acquired by humans as members of society (Fukuyama, 1995, Hampden-Turner and Trompenaars, 1994, Lessem and Neubauer, 1994, Fukuyama 1995). Cultural differences even exist within one geographical region such as a country, since because people within a country do not all have identical cultural characteristics and the variation can be seen as a normal distribution (Trompenaars and HampdenTurner 1997). Therefore, these cultural dimensions could also be applied within a country, especially for multicultural counties, such as the USA, India, and China, whose many regions have various mini-cultures of their own (Hall 1990).

*Corresponding author. Email: hd199@mails.tsinghua.edu.cn 
This study first conducted a laboratory experiment to investigate the effects of CS and TO on people's perception of and proficiency in using notification systems, with regard to three critical parameters: comprehension, interruption and reaction (McCrickard et al. 2003). Then the implications of these effects in a typical type of notification (a virus attack warning provided by anti-virus software) were studied through focus group discussions. The results should prove useful to aid designers in creating more effective and appealing ways to notify or warn users, depending on their different CS and TO.

\section{Background literature}

\subsection{Communication style and time orientation}

Culture differences, which affect virtually all of human behaviour (Terpstra and David 1985, Ferraro 1994), and their relationship with information technology, are emerging as a popular subject of research. Many researchers, especially those in the field of humancomputer interaction (HCI) are devoting their efforts towards how to make computer-user interfaces sensitive to different classes of users who have different cultural styles, to enable them to perform their tasks with computers safely, effectively, efficiently and pleasurably (Hofstede 1991, Choong 1996, Kress and van Leeuwen 1996, Prabhu and Harel 1999, Gould 2001, Rose et al. 2003, Trafton et al. 2003, Efendioglu and Yip 2004, Smith et al. 2004, Ding et al. 2005, Galletta et al. 2006).

Cultural differences can be seen in ways of processing information and attitudes towards time and space (Rau and Liang 2003). A popular cultural framework was proposed by Hall (Hall 1983, 1987, 1990), in which he stated that all cultures can be situated in relation to one another through two cultural dimensions: CS and TO.

\subsubsection{High/low context communication style}

This item concentrates on the amount of information a person can comfortably manage. In high-context cultures, information is more likely to be transmitted in non-verbal and indirect ways. Therefore, listeners have to pay careful attention because important facts have to be obtained by 'reading between the lines'. Information passes spontaneously and in wide networks. Therefore, the information flow works fast and people tend to be informed on many subjects. On the other hand, in low-context cultures, information is communicated in a very direct way. Verbalised statements that follow a given plan are usual. This is why the information flow tends to be very slow.
Moreover, people tend not to be informed on subjects outside of their own interests.

\subsubsection{Monochronic/polychronic time orientation}

This dimension shows that different cultures have different perceptions of time. Members belonging to monochronic societies are more likely to have a linear time perception. They are used in doing one item at a time and take time commitments seriously. In contrast, polychronic societies do not have a linear but rather a cyclic time perception. They do not mind doing several things simultaneously and consider time frames as useful, but are not bothered if they cannot complete their work within them.

A questionnaire measuring Hall's concepts of these two dimensions has been developed by Honeywell Labs (Plocher et al. 2001) and validated by previous research (Plocher et al. 2001, Rau and Liang 2003). The questions in the questionnaire were developed from the observations and descriptions that are presented in Hall's books as prime examples of these two cultural variables. The questionnaire has been translated into Chinese and was used in this study.

\subsection{Notification system}

Notification systems deliver ever-changing and valuable information while allowing users to perform the current activities in an efficient and effective manner (McCrickard and Chewar 2003). An increasing number of peripheral displays and notification systems have been designed, like Microsoft's Office Assistant, Toast (Zhang et al. 2005), Info-Lotus (Zhang et al. 2005), Sideshow (Cadiz et al. 2001), Scope (Dantzich et al. 2002), Irwin (McCrickard 1999) and even hardware devices like Ambient Orb (Hsieh and Mankoff 2003). These types of displays share the common design goal of providing the user with access to additional information without requiring excessive levels or prolonged periods of attention (McCrickard et al. 2003).

Some studies have been conducted to investigate how to optimise the managing policy to deliver notifications. Fogarty et al. (2005a) claimed that many notification systems tended to interrupt at inappropriate times because of not being able to determine when an interruption is appropriate. Fogarty and Hudson then further developed sensor-based model to estimate human interruptibility (Fogarty et al. 2005b). Bailey and his co-workers' studies (Bailey and Konstan 2006, Iqbal and Bailey 2008) indicated that deferring presentation of peripheral information and scheduling notification at breakpoint can reduce disruption and frustration. 
There also has been some research focused on developing evaluation techniques for ambient displays and notification systems, like Mankoff et al.'s set of discount formative techniques (Mankoff et al. 2003) and McCrickard et al.'s notification system categorisation framework (McCrickard et al. 2003). McCrickard and his team developed and proposed the IRC framework as a guiding conceptual approach (McCrickard and Chewar 2003, McCrickard et al. 2003) - a unifying framework for understanding, classifying, analysing, developing, evaluating and discussing notification systems, which explores the balance between three parameters: interruption, reaction and comprehension. The interruption parameter (I) was defined as an event prompting transition and reallocation of attention focus from a task to a notification. The reaction parameter $(\mathrm{R})$ was considered as the speed and accuracy of the user's response to the stimuli provided by the notification system. The comprehension parameter $(\mathrm{C})$ represented the rate at which users remember and make sense of the information provided by the notification system at a later time.

McCrickard and his team conducted a usability evaluation for one of Microsoft's notification systems (Scope). According to the IRC model, Scope should act both as an alarm, supporting high interruption and reaction but low comprehension (IRC 110), and as an ambient display, supporting high comprehension but low reaction and interruption (IRC 001) (McCrickard et al. 2003).

Chewar claimed that the IRC model can be implemented in system description, interface evaluation and design comparison and reuse of notification systems, and he classified existing notification systems with the IRC model (Chewar 2003).

Zhang and Tu implemented the IRC model in their study to evaluate the usability of the Microsoft Office Outlook 2003 email notification system, which is commonly known as 'Toast'. They found that Toast provided the users with a low level of comprehension, a medium to high level of interruption and a low to medium level of reaction. On the basis of this, they developed a new notification system (InfoLotus), which was also evaluated with the IRC model and got better results than Toast (Zhang et al. 2005).

As reported in the authors' previous conference article (Huang et al. 2007), TO could affect users' perceived interruption and reaction of a notification system. It indicated the necessity to conduct a more comprehensive study covering more related factors. In this study, CS and TO were jointly considered. And all the three factors of the IRC model were investigated.

\subsection{Anti-virus software}

The problem of computer viruses is of great concern to computer users, and many of them rely on anti-virus software to protect their computers (Hampden-Turner and Trompenaars 1994). Anti-virus software usually runs in the background and scans disks for possible viruses (Post and Kagan 1998). Once a virus attack is detected, the anti-virus software will usually alert the users and remind them to take a certain action. There are many anti-virus software products, e.g. Norton Antivirus, Kaspersky Antivirus, PC-cillin, Bitdefender, F-Secure Anti-virus, ESET Nod32, McAfee VirusScan and AVG Antivirus (TopTenREVIEWS 2007). Many criteria can be used to evaluate and select an anti-virus software product (Mamaghani 2002), such as its ability to detect and remove viruses, the ease of installation, the ease of use, the technical support and the cost. However, there are also great differences in the ways that the anti-virus software alerts users of viruses, which can also influence the users' satisfaction with the anti-virus software. Recently, some studies conducted by Edwards and his co-workers (Payne and Edwards 2008, Stoll et al. 2008) also highlighted the importance to investigate how to better inform users of security accidents.

\section{Hypotheses}

\section{Hypothesis 1a}

Users who tend to exhibit a low-context CS exhibit higher levels of comprehension of notification systems. Their ability to remember and make sense of the information provided by the notification system is better than that of high-context users.

\section{Hypothesis $1 \mathrm{~b}$}

Users who tend to have a monochronic TO exhibit higher levels of comprehension of notification systems. Their ability to remember and make sense of the information provided by the notification system is better than that of polychronic users.

For high-context communication, the main emphasis is not laid on the passing on of information, as most of it lies in the context. However, for low-context communication, the main focus of interest is information, and the context is relatively unimportant, as notification systems contain more information and fewer contexts (as Figure 1 shows). Thus, low-context communication users should have a better ability to remember and make sense of the information provided by the notification system than high-context communication users.

According to Hall, there is a correlation between low-context CS and monochronic TO (Hall 1990). 


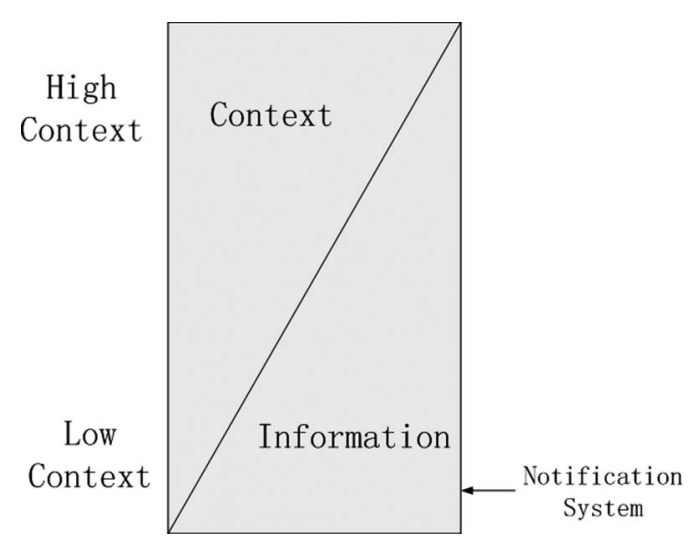

Figure 1. High-context and low-context communication.

Therefore, hypothesis $1 \mathrm{~b}$ was also developed based on hypothesis 1a.

\section{Hypothesis $2 a$}

Users who tend to have a monochronic TO perceive a higher level of interruption for notification systems than users who tend to have a polychronic TO.

\section{Hypothesis $2 b$}

Users who tend to have a low-context CS perceive a higher level of interruption for notification systems than users who tend to have a high-context CS.

\section{Hypothesis 3a}

Users who tend to have a polychromic TO exhibit a higher level of reaction to notification systems than users who tend to have a monochronic TO.

\section{Hypothesis $3 b$}

Users who tend to have a high-context CS exhibit a higher level of reaction to notification systems than users who tend to have a low-context CS.

Previous studies have revealed that people's TO can influence their perception or attitude in an HCI environment. For example, in the case of an internet surfing, monochronic users are more concerned with download delays that polychronic users (Rose et al. 2003). Monochronic users prefer to do one thing at a time, working on a task until it is finished. To a monochronic user, switching back and forth from one activity to another is not only wasteful and distracting but also uncomfortable. Thus, they tend to avoid events prompting transition and reallocation of attention focus from a task to the notification, perceive higher levels of interruption of notification messages, and tend to avoid immediately responding to notification messages.

In contrast, polychronic users love to work on more than one thing at a time. To them, switching from one activity to another is both stimulating and productive. Thus, they perceive lower levels of interruption of notification messages and prefer a rapid and accurate response to the stimuli provided by the notification system.

According to Hall, there is a correlation between high-context and polychronic as well as low-context and monochronic (Hall 1990). Therefore, hypotheses $2 \mathrm{~b}$ and $3 \mathrm{~b}$ were also developed based on hypotheses $2 \mathrm{a}$ and $3 \mathrm{a}$.

\section{Methodology}

An experiment was designed to test the proposed hypotheses and examine how the TO and CS affect participants' perception of and proficiency in using the notification system. The methodology associated with the experiment is discussed as follows.

\subsection{Participants}

Eighty-three undergraduate and graduate students from Tsinghua University, Beijing, China, were invited to fill Honeywell Hall's cultural dimension questionnaire. According to their answers, they were labelled as high/low context CS and polychronic/monochronic TO. Among them, eight high-context and polychronic $(\mathrm{H}-\mathrm{P})$ respondents, eight high-context and monochronic $(\mathrm{H}-\mathrm{M})$ respondents, eight low-context and polychronic (L-P) respondents and eight low-context and monochronic (L-M) respondents were randomly selected as participants to conduct the tasks described in the next section. All the participants had at least 1 year's experience with computers, with an average of $5 \mathrm{~h}$ per week. The age of the participants ranged from 20 to 28 years old $($ mean $=22.9, \mathrm{SD}=2.02)$. Twenty participants were males and 12 participants were females.

\subsection{Task}

The experiment tasks were designed to simulate a situation that participants need to allocate attention between tasks. The participants were asked to complete a primary task (a simple game in which they 'hit' an image of a dog) while monitoring the information displayed on the notification system as the secondary task. The game lasted for $5 \mathrm{~min}$. The participants' hit rate with and without notification messages displayed were recorded automatically. After the test, they were asked to fill out a questionnaire with questions related to the information on the notification system, subjective rating of the interruption and the general attitudes towards the notification system. 


\subsubsection{Hitting the dog game (primary task)}

In the game, a dog emerged from one of nine holes randomly, and the user was required to click on the dog as soon as possible. Every time the user 'hit' the dog in time, 10 points would be collected. This simple game ensured that the primary task only measured the motor skills of the users, regardless of their other capabilities, such as software proficiency. To familiarise themselves with the task, they were allowed to practise for 2 to $3 \mathrm{~min}$.

\subsubsection{Notification monitoring task (secondary task)}

While playing the hitting the dog game, participants were asked to observe the information displayed in the bottom right corner of the screen as their secondary task. They were informed of a scenario in which the user was a group member receiving a message from his/her manager to attend an activity on the weekend. Some team members replied to give suggestions on the time, location and content of the activity. Then, the users started tracking that series of notification messages while performing the primary task (the hitting the dog game) for $5 \mathrm{~min}$. There were 26 messages from the manager and from 4 other team members: Yao Ming, Liu Xiang, Liu Dehua and Zhao Wei (in this study, the team members were given the names of celebrities, as the users were familiar with them and required little time to recall them). The messages could be categorised into two types: messages that contained critical information, which was helpful for answering the following questionnaire, and messages that did not contain critical information, which may be useless for answering the following questionnaire. However, participants were not able to judge the type of messages without reading them. (The messages are shown in the Appendix.) The hitting the dog game and the notification system prototype were designed with Macromedia Flash ${ }^{\mathrm{TM}}$ MX 2004, and are shown in Figures 2 and 3.

The performance of the participants in the game, including their hit rate with and without the messages appearing, was recorded and used as an objective rating for the interruption level. Each participant was asked to answer a questionnaire after finishing the task.

\subsection{Dependent variables}

The data were collected through recording participants' performance in the hitting the dog game and their answers on the questionnaires. Three dependent variables were monitored: comprehension, interruption and reaction.

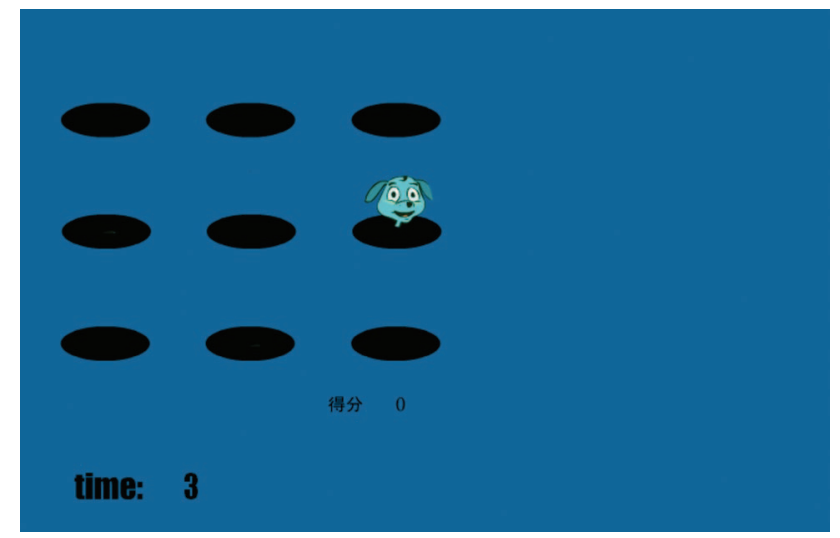

Figure 2. The hitting the dog game, without notification messages.

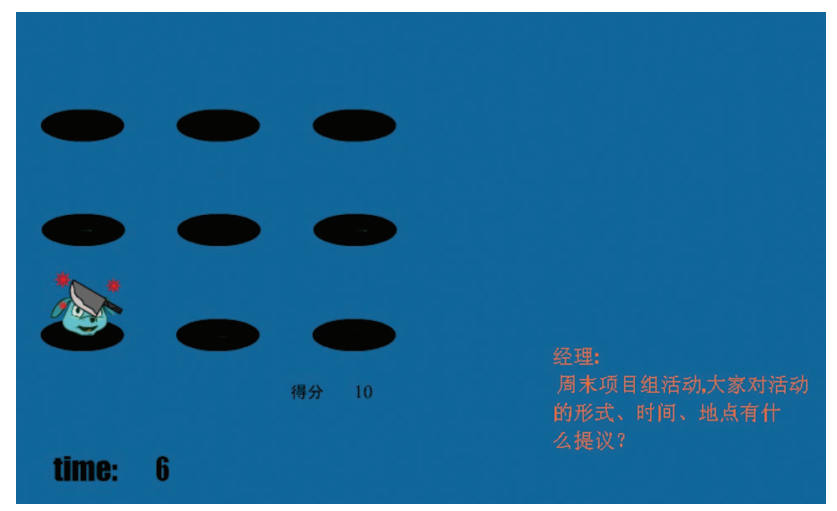

Figure 3. The hitting the dog game, with notification messages.

\subsubsection{Comprehension level}

Comprehension level was the variable to evaluate the participants' ability to remember and make sense of the information provided by the notification system. The participants read notification messages during the hitting the dog game and after the game they were asked to answer the following questions: 'Where are you going for the weekend activity?', 'What is the activity?', 'What is the meeting time?', 'Who suggested going mountain climbing?', 'What did the manager remind you to do?' and so on. There were eight questions in all, including seven multiple choice questions and one essay question. Each correct answer was worth 1 point, while a wrong answer got 0 points. The total points the participant earned were viewed as the measurement of his/her comprehension level.

\subsubsection{Interruption level}

Interruption level was the variable to evaluate how serious the participants perceived the interruption by 
the notification messages to be. This study used two kinds of measurement to evaluate the interruption level. One was objective measurement. The participants' hit rates with and without the messages appearing during the hitting the dog game were recorded separately, and the decrease (comparing the hitting rates with and without messages appearing) of the hitting rate was calculated. This decreasing rate (in percentage) was viewed as the objective measurement of the user's interruption level. The other was subjective measurement. The participants were asked to evaluate how seriously they were interrupted by the notification messages during the hitting the dog game. The scale was from 1 to 7 , with 1 being the least and 7 being the most. This evaluation by the participant was viewed as the subjective measurement of the user's interruption level.

\subsubsection{Reaction level}

Reaction level was the variable to evaluate participants' desire of transiting and reallocating attention focus from a task to the notification. The participants were asked to answer six questions, which were designed to measure the reaction level of the participants to a peripheral display, e.g. "while you are editing files or programming on the computer, if a notification system prompts you that you have received a new message, what would you do with the prompt? A, check the message immediately; $\mathrm{B}$, check the messages after they have accumulated to a certain number; C, check the messages after a certain time; $\mathrm{D}$, ignore the prompt'. Different choices were assigned different points (A was worth 4 ; B, 3; C, 2; and D, 1); the higher the point, the higher level of reaction. All the points for the six questions are added together, and the total points were used to measure the participants' reaction level.

\subsection{Independent variables}

Two independent variables were manipulated in testing the proposed hypotheses:

- CS with two levels (high-context or low-context).

- TO with two levels (polychronic or monochronic).

Participants' CS and TO were measured by Honeywell Hall's cultural dimension questionnaire (Plocher et al. 2001). The questions in the questionnaire centred around work situations such as adhering to schedules, conduct of meetings, preferred work environment, and the procedural versus intuitive approach to job tasks. All the questions have been checked to be suitable to be answered by Chinese college students.

\subsection{Procedures}

The experiment was conducted with the following procedures:

(1) Prior to the test, the demographic information of the participants was collected, including name, gender, age, education, and so on.

(2) Then the participants were given the cultural dimension questionnaire.

(3) A short practice and explanation session for the notification system was provided for the participants.

(4) The participants conducted the task, which took about $10 \mathrm{~min}$.

(5) The questionnaire was given to the participants after they had completed the task. This entire process took the participants around $25 \mathrm{~min}$ to complete.

\section{Results}

\subsection{Respondents' time orientation and communication style}

In total, 83 students from Tsinghua University had filled the questionnaire to measure their TO and CS. There were 16 TO questions with a Likert scale from one to seven (four for the neutral). The score was calculated by adding up the answers to the 16 questions for each participant. The higher the score, the more monochronic the participant. The score for neutral TO was $64(4 \times 16$ questions). All participants scoring over 64 were categorised as having monochronic TO. The remaining participants were categorised as having polychronic TO. The respondents' average scores of TO ranged from 43 to 91 (mean $72.4, \mathrm{SD}=8.96)$. There were 16 respondents categorised as having polychronic TO and 67 respondents categorised as having monochronic TO.

There were $10 \mathrm{CS}$ questions with a Likert scale from one to seven (four for the neutral). The score was calculated by adding up the answers to the 10 questions for each participant. The higher the score, the higher the participant's communication context. The score for neutral CS was $40(4 \times 10$ questions). All participants scoring over 40 were categorised as high-context communication. The remaining participants were categorised as low-context communication. The respondents' average scores of CS ranged from 22 to 59 (mean $=37.1, \mathrm{SD}=6.82)$. There were 27 respondents categorised as high-context 
communication and 56 respondents categorised as low-context communication.

The internal consistency of the 16 TO items and 10 CS items in the questionnaire, using Cronbach's $\alpha$, was 0.71 and 0.76 . The high level of internal consistency suggests high reliability and validity of the results described in subsequent sections of this article.

The respondents could be divided into four groups: high-context and polychronic (H-P) group, highcontext and monochronic (H-M) group, low-context and polychronic (L-P) group and low-context and monochronic (L-M) group. To test the proposed hypotheses, eight respondents from each of the four groups (in total $8 \times 4=32$ respondents) were randomly selected as participants to perform the experiment task. Their scores of TO and CS are shown in Table 1.

\subsection{Effects of communication style and time orientation on comprehension}

To investigate how people's CS and TO can affect their comprehension of notification systems, a multiple linear regression analysis was used. As shown in Table 2, the regression analyses showed CS to be a good predictor of people's comprehension of notification systems: low-context communication users' ability to remember and make sense of the information provided by the notification system was better than that of high-context users. TO was not found to have significant effect as a predictor of people's comprehension of notification systems.

\subsection{Effects of time orientation and communication style on interruption}

To investigate how people's TO and CS can affect their perception of interruption from notification systems, multiple linear regression analyses were used. This research used two kinds of measurement to measure the participants' perception of the interruption level. One was the participants' subjective evaluation of the severity of the interruption. The scale was from 1 to 7 , with 1 being the least severe and 7 being the most severe. The other was the decreasing rate of the participants' hit rate with and without notification messages appearing, which can be viewed as an objective measurement. Using these two measurements as dependent variables, two separate regression analyses were conducted.

Table 1. Participants' time orientation and communication style.

\begin{tabular}{|c|c|c|c|c|c|c|c|c|c|}
\hline \multirow[b]{2}{*}{ Participant } & \multicolumn{2}{|c|}{ Time orientation } & \multicolumn{2}{|c|}{$\mathrm{CS}$} & \multirow[b]{2}{*}{ Participant } & \multicolumn{2}{|c|}{ Time orientation } & \multicolumn{2}{|c|}{$\mathrm{CS}$} \\
\hline & Score $^{\mathrm{a}}$ & $\overline{\text { Category }}$ & Score $^{\mathrm{b}}$ & $\overline{\text { Category }}$ & & Score & $\overline{\text { Category }}$ & Score & $\overline{\text { Category }}$ \\
\hline 1 & 43 & $\mathrm{P}$ & 59 & $\mathrm{H}$ & 17 & 66 & M & 42 & $\mathrm{H}$ \\
\hline 2 & 54 & $\mathrm{P}$ & 47 & $\mathrm{H}$ & 18 & 70 & M & 46 & $\mathrm{H}$ \\
\hline 3 & 60 & $\mathrm{P}$ & 46 & $\mathrm{H}$ & 19 & 73 & M & 43 & $\mathrm{H}$ \\
\hline 4 & 61 & $\mathrm{P}$ & 45 & $\mathrm{H}$ & 20 & 76 & M & 50 & $\mathrm{H}$ \\
\hline 5 & 62 & $\mathrm{P}$ & 46 & $\mathrm{H}$ & 21 & 77 & M & 41 & $\mathrm{H}$ \\
\hline 6 & 63 & $\mathrm{P}$ & 43 & $\mathrm{H}$ & 22 & 77 & M & 50 & $\mathrm{H}$ \\
\hline 7 & 63 & $\mathrm{P}$ & 45 & $\mathrm{H}$ & 23 & 79 & M & 42 & $\mathrm{H}$ \\
\hline 8 & 64 & $\mathrm{P}$ & 41 & $\mathrm{H}$ & 24 & 82 & M & 41 & $\mathrm{H}$ \\
\hline 9 & 49 & $\mathrm{P}$ & 22 & $\mathrm{~L}$ & 25 & 65 & M & 29 & $\mathrm{~L}$ \\
\hline 10 & 60 & $\mathrm{P}$ & 24 & $\mathrm{~L}$ & 26 & 68 & M & 36 & $\mathrm{~L}$ \\
\hline 11 & 61 & $\mathrm{P}$ & 36 & $\mathrm{~L}$ & 27 & 70 & M & 29 & $\mathrm{~L}$ \\
\hline 12 & 62 & $\mathrm{P}$ & 32 & $\mathrm{~L}$ & 28 & 78 & $\mathrm{M}$ & 38 & $\mathrm{~L}$ \\
\hline 13 & 62 & $\mathrm{P}$ & 36 & $\mathrm{~L}$ & 29 & 80 & M & 36 & $\mathrm{~L}$ \\
\hline 14 & 63 & $\mathrm{P}$ & 39 & $\bar{L}$ & 30 & 82 & M & 36 & $\mathrm{~L}$ \\
\hline 15 & 64 & $\mathrm{P}$ & 34 & $\mathrm{~L}$ & 31 & 83 & M & 34 & $\mathrm{~L}$ \\
\hline 16 & 64 & $\mathrm{P}$ & 39 & $\mathrm{~L}$ & 32 & 84 & M & 39 & $\mathrm{~L}$ \\
\hline
\end{tabular}

CS, communication style; $\mathrm{P}$, polychronic; $\mathrm{M}$, monochromic; 'L', low-context; 'H', high-context.

${ }^{\text {a }}$ The score of neutral time orientation is: $4 \times 16$ (questions) $=64$.

${ }^{\mathrm{b}}$ The score of neutral CS is: $4 \times 10$ (questions) $=40$.

Table 2. Regression analysis testing the relationship among comprehension, time orientation and communication style.

\begin{tabular}{lcccr}
\hline Dependent variable & $R^{2}$ & Independent variables & Standardised coefficients & $t$ \\
\hline Comprehension & 0.198 & Time orientation & 0.104 & 0.627 \\
& & CS & -0.427 & 0.536 \\
\hline
\end{tabular}

CS, communication style.

Note: The italicised values are statistically significant (value $<0.05$ ). 
The results of regression analysis for the subjective measurement are shown in Table 3. TO was found to be a good predictor of peoples' subjective evaluation of interruption: monochronic users perceived higher levels of interruption of the notification messages than polychronic users. CS was not found to have significant effect as a predictor of peoples' subjective evaluation of interruption.

The results of regression analysis for the objective measurement are shown in Table 4. TO was found to be a good predictor of peoples' objective evaluation of interruption, indicating that the appearance of notification messages had greater influence on monochronic participants' performance of the primary task than on polychronic participants. CS was not found to have significant effect as a predictor of peoples' objective evaluation of interruption.

\subsection{Effects of time orientation and communication style on reaction}

To investigate how people's TO and CS can affect their reaction level to notification systems, a multiple linear regression analysis was used. As shown in Table 5, the results of regression analysis showed TO to be a good predictor of people's reaction level to notification systems: polychronic users prefer rapid and accurate responses to the stimuli provided by the notification system, while monochronic users tend to avoid rapid and accurate responses. CS was not found to have significant effect as a predictor of people's reaction level to notification systems.

\subsection{Summary and discussion}

Based on the analysis above, some conclusions can be drawn. Hypothesis 1a was supported, which means the CS can affect the users' comprehension of the notification information; users who tended to exhibit low-context communication characteristics achieved higher levels of comprehension of notification systems. Hypothesis 2a was also confirmed, which means that TO can affect the users' perception of interruption; users who tended to have a monochronic TO perceived higher levels of interruption from notification systems than users who tended to have a polychronic TO. Hypothesis 3a was confirmed, too, which means the user's TO could affect their reaction; polychronic users preferred rapid and accurate responses to the stimuli provided by the notification system, while

Table 3. Regression analysis testing the relationship among subjective interruption, time orientation and CS.

\begin{tabular}{lcccr}
\hline Dependent variable & $R^{2}$ & Independent variables & Standardised coefficients & $t$ \\
\hline Subjective interruption $^{\mathrm{a}}$ & 0.301 & Time orientation & 0.549 & 3.533 \\
& & CS & 0.050 & 0.001 \\
& & & 0.748 \\
\hline
\end{tabular}

${ }^{a}$ Measured by the participants' subjective evaluation of the severity of the interruption.

The scale was from 1 to 7 , with 1 being the least severe and 7 being the most severe.

CS, communication style.

Note: The italicised values are statistically significant (value $<0.05$ ).

Table 4. Regression analysis testing the relationship among objective interruption, time orientation and communication style.

\begin{tabular}{lcccr}
\hline Dependent variable & $R^{2}$ & Independent variables & Standardised coefficients & $t$ \\
\hline Objective interruption $^{\mathrm{a}}$ & 0.181 & Time orientation & 0.426 & Sig. \\
& & CS & 0.023 & 0.017 \\
& & & 0.892 \\
\hline
\end{tabular}

${ }^{a}$ Measured by the decreasing rate of the participants' hit rate with and without the appearing of notification messages.

CS, communication style.

Note: The italicised values are statistically significant (value $<0.05$ ).

Table 5. Regression analysis testing the relationship among reaction, time orientation and communication style.

\begin{tabular}{lcccr}
\hline Dependent variable & $R^{2}$ & Independent variables & Standardised coefficients & $t$ \\
\hline Reaction $^{\mathrm{a}}$ & 0.239 & Time orientation & -0.486 & -2.995 \\
& & CS & -0.081 & -0.501 \\
\hline
\end{tabular}

${ }^{a}$ Sum of participant's points for the six questions measuring the reaction level of the participants to a peripheral display.

The higher the point, the higher level of reaction.

The internal consistency of the questionnaire, using Cronbach's $\alpha$, was 0.89 .

CS, communication style.

Note: The italicised values are statistically significant (value $<0.05$ ). 
monochronic users tended to avoid responding. Hypotheses $1 \mathrm{~b}, 2 \mathrm{~b}$ and $3 \mathrm{~b}$ were not supported by the experiment results.

Responses to the cultural questionnaire indicated a tendency for monochronic TO and low-context CS in this particular group of Chinese college students. This runs contrary to Hall's speculations, who claimed that Chinese people represented a high-context and polychronic culture in general (Hall 1987, 1990, Kim et al. 1998). That might be due to some limitation of the experiment samples, since all the participants were undergraduate and graduate students from Tsinghua University, which is a science and engineering university and has many courses of American style. It might also reflect the effects of the rather dramatic intersection of social and political influences on China over the past 30 years, like the reforming and openingup, the family planning policy, and western social and economic influences.

According to Hall, there is a correlation between high-context and polychronic as well as low-context and monochronic (Hall 1990). A correlation analysis for the 83 respondents' scores of TO and CS was conducted, and the results also showed that the correlation coefficient was statistically significant $(r=-0.29, \quad p<0.01)$. However, the results of regression analyses showed that people's comprehension of notification system was only affected by their CS (see Table 2), while people's perceived interruption and reaction of notification system were only affected by their TO (see Tables 3 and 5). That might be caused by the difference between people's ability (user being able to allocate attention between tasks efficiently) and preference (user preferring to allocate attention between tasks or focus on single task). In the experiment, the measurement of participants' comprehension of notification system was measuring their ability, while the measurement of participants' interruption and reaction of notification system were measuring their preference. It might provide some hints that people's CS should be more related to their ability, while people's TO should be more related to their preference. Further research on this question is necessary.

\section{Focus group discussions}

The above experimental results actually indicated that users with different CS and TO could have different ability and preference of allocating attention between tasks. The success of a notification system hinges on how well it can help users to allocate their attention between their current activities and the incoming notification, such as the arrival of new email, instant messages from friends and warnings of virus attacks.
A notification system should be adapted to user's CS and TO.

Anti-virus software relies heavily on notification system. Once a virus attack is detected, the anti-virus software will alert the users and remind them to take a certain action. The satisfaction of an anti-virus software perceived by user depends not only on its ability of virus detection, but also on how well it gives alerts and notifications. Therefore, to investigate the implications and applications of above findings, the specific type of notification system - virus attack alerts provided by anti-virus software - was selected for further discussions among groups of participants.

Focus group discussions were carried out to investigate the application of this study in anti-virus software and to add to the understanding of how CS and TO influence users' perception of, feelings about and attitude towards virus alerts provided by anti-virus software. In a focus group, a small group of people with similar experiences gather to freely and spontaneously discuss a central topic of interest to themselves and to the researcher. Focus groups have been recognised as an excellent data collection tool for exploratory studies and program development (Krueger and Casey 2000, Fern 2001, Heary and Hennessy 2002).

\subsection{Methodology}

Four focus groups were formed: a high-context CS group, a low-context CS group, a polychronic TO group and a monochronic TO group. The participants were recruited from Tsinghua University in Beijing, China. They were asked to answer the cultural dimensions questionnaire (Plocher et al. 2001) first. Only people who had extremely high-/low- context CS or polychronic/monochronic TO were recruited. A total of 20 participants were recruited. Five participants (three males and two females) with high CS scores $(>40)$ were assigned to the high-context CS group; five participants (three males and two females) with low CS scores $(<30)$ were assigned to the lowcontext CS group; five participants (two males and three females) with high TO scores $(>80)$ were assigned to the monochronic TO group; and five participants (two males and three females) with low TO scores $(<60)$ were assigned to the polychronic TO group. All the participants had similar levels of education and similar ages, ranging from 20 to 27.

The focus group discussions lasted between 1 and $1.5 \mathrm{~h}$ and were facilitated by a moderator. The topics of the focus groups were: (1) participants' experience of information security breaches; (2) the advantages and disadvantages of the anti-virus software they use; (3) the ways that anti-virus software should give alarms; and (4) how anti-virus software should deal with 
detected viruses? The analysis was based on the notes taken during the focus group sessions.

\subsection{Findings}

The participants with different TOs and CSs expressed different opinions about and requirements of anti-virus software. Comments and suggestions for designing notifications provided by anti-virus software are summarised and presented by cultural dimensions in the following paragraphs.

\subsubsection{Monochronic time orientation group}

Monochronic users were apt to become impatient and irritated when the anti-virus software kept giving alarms and interrupting their ongoing work. In most cases, they would not react to the alarms immediately. The participants suggested the following features to enhance monochronic users' satisfaction with the antivirus software:

- Do not interrupt the users' ongoing work too frequently with virus attack warnings. Anti-virus software should be able to deal with most of the detected virus attacks automatically; only the most serious and urgent alarms should be given to the users immediately.

- Giving alarms with sounds is not necessary; shrill sounds should especially be avoided.

- Avoid giving alarms with pop-up windows in the centre of the computer screen. It is better to use warning messages that appear at the corner of the screen.

- Use subdued colours (e.g. blue), which do not attract as much attention.

- Use linear navigation in the interface for user to conduct tasks. For example, use tabular and functional design for user to check the results of virus scanning.

- Organise the information in the alarming window with apparent and static way. Designers can expect that user will like to see all the necessary information without any mouse-over and click on the window.

- Provide the option of 'don't ask me again in the future'.

\subsubsection{Polychronic time orientation group}

Polychronic users felt less uncomfortable with being interrupted by virus attack alerts. For them, 'getting warnings in time' was more important than 'keeping work from being interrupted'. They were also more willing to react to the virus alerts. The polychronic participants' comments and suggestions for anti-virus software are summarised as follows:

- Warn the users immediately when virus attacks are detected.

- Sound is desirable for virus attack alerts.

- Messages should use bright colours (e.g. yellow and red), which attract more attention.

- The users should be given options of actions to select to respond to the virus alert.

- Feedback is important. Information about the results of actions should be provided.

- Use parallel navigation in the interface for user to conduct tasks. For example, use layer-uponlayer design.

- Organise the information in the alarming window with dynamic way. Designers can expect that user will be likely to find the information through exploration of the window and performance of mouse-overs and clicks.

\subsubsection{High-context communication style group}

High-context users were apt to perceive the security situation of their computers through multiple channels, e.g. the frequency of virus alerts, the wording of warning messages, the colour of warning messages, the warning sounds and the symbols. The high-context participants' comments and suggestions for anti-virus software are summarised as follows:

- Very frequent alarms, even if the alarms are not serious, will make them feel stressful.

- Severe wording of warning messages will make them feel that they are being threatened. Calm and polite wording is preferable.

- Different colours and symbols should be used to represent different security situations. An example was given by the participants: the symbol of a green traffic light when the system is safe; a yellow light for a somewhat dangerous situation; and a red light for a very serious threat to computer security.

- Virus alerts should include sounds. However, shrill sounds should be avoided.

\subsubsection{Low-context communication style group}

Low-context users were apt to judge the security situation of their computers through the explicit messages provided by the anti-virus software, and they wanted to know detailed information about the detected virus. The low-context participants' comments and suggestions for anti-virus software are summarised as follows: 
Table 6. Summary of the focus group discussion results.

\begin{tabular}{|c|c|c|c|c|}
\hline \multirow{2}{*}{$\begin{array}{l}\text { Requirements proposed } \\
\text { by the participants }\end{array}$} & \multicolumn{2}{|c|}{ Time orientation } & \multicolumn{2}{|c|}{ CS } \\
\hline & Monochronic & Polychronic & Low-context & High-context \\
\hline Level of automation & High & Low & High & Low \\
\hline Use of colour & Subdued colours & Bright colours & & Use various colours \\
\hline Use of sound & Not necessary & Necessary & Not necessary & Necessary \\
\hline Location of the pop-up & Screen corner & Corner or centre & & \\
\hline Action feedback & & Necessary & & \\
\hline Navigation design & Tabular and functional & Layer-upon-layer & & \\
\hline Information organisation & Apparent and static & Dynamic & & \\
\hline Wording of message & & & $\begin{array}{l}\text { Avoid dramatic } \\
\text { wording }\end{array}$ & Calm and polite \\
\hline Use of symbols & & & Not necessary & Use various symbols \\
\hline Option to know details & & & Necessary & \\
\hline
\end{tabular}

CS, communication style.

- The presentation of the warning should be as simple as possible. The uses of colour, symbols or animation are not necessary.

- Dramatic wording should be avoided; the warning should just provide the facts objectively.

- Users should be provided with the option to know detailed information about the detected virus, such as the origin of the virus, the possible damage that the virus can cause and the danger level of the virus.

The results of the focus group discussions showed that users' TO and CS influenced their perception of, attitudes towards and requirements of virus alerts provided by anti-virus software. Monochronic users easily became impatient and irritated with virus alerts and tended to avoid immediate reaction to the alerts, while polychronic users were more comfortable with interruptions and were willing to react to the alerts. High-context users were apt to perceive the security situation of their computers through multiple channels, while low-context users relied on the explicit warning messages. These differences led to distinctly different requirements for the notification system of anti-virus software, including the level of automation, choice of colour, usage of sound, location of the popup window, message wording, usage of symbols, amount of information to be provided and usage of feedback. The results are summarised and shown in Table 6.

\section{Conclusions}

This study has revealed that users' CS and TO do affect their perception of and proficiency in using notification systems; users with a low-context CS are able to remember and make sense of the information provided by the notification system better than users with a high-context CS. Polychronic users perceive lower levels of interruption of the notification messages than monochronic users, and polychronic users prefer rapid and accurate responses to the stimuli provided by the notification system while monochronic users tend to avoid them. The application of these findings in the field of a specific type of notification system - warning of virus attacks provided by anti-virus software - were investigated by focus group discussions. Suggestions and recommendations for the design of virus alerts were summarised. The results could prove useful to aid designers in creating more effective and attractive ways to give notification or warnings to users with different TO and CS.

The results of questionnaire about TO and CS in this study also suggested that, at least for some specific groups of people like young college students, some of the assumptions about the cultural pattern of Chinese people raised by Hall before the 1990s might not be entirely valid now. In the past 30 years, the Chinese social circumstances have been changed a lot. For example, for the young generation in China, most young people do not have siblings, and many of them have been significantly affected by western culture; they probably have different cultural patterns than traditional Chinese. All the above suggestions should be applied carefully and further research on the cultural patterns of younger generations is necessary.

Many studies have been conducted to investigate how to make computer-user interfaces sensitive to users who have different cultural styles, most of which aimed to compare users from two or more countries or regions (e.g. Rose et al. 2003, Galletta et al. 2006). The results of this study indicated that there is a variety of cultural style even within people from the same country. Thus, different user interface designs for notification system may be necessary even within a 
country, especially for multicultural counties, such as the USA, India, and China, whose many regions have various minicultures of their own.

\section{Acknowledgements}

This research was supported by the IBM China Research Laboratory. The authors thank all the participants for participating in the experiment and openly discussing their opinions.

\section{References}

Bailey, B.P. and Konstan, J.A., 2006. On the need for attention aware systems: measuring effects of interruption on task performance, error rate, and affective state. Journal of Computers in Human Behavior, 22 (4), 709-732.

Cadiz, J.J., et al., 2001. Sideshow: providing peripheral awereness of important information. Tech. Rep. MSRTR-2001-83, Microsoft Research, Collaboration, and Multimedia Group. September.

Chewar, C.M., 2003. Modeling user goals for notification system interfaces. Unpublished Proposed Research for $\mathrm{PhD}$ Degree, Virginia Polytechnic Institute and State University.

Choong, Y.-Y., 1996. Design of computer interfaces for the Chinese population. Doctoral Dissertation. Unpublished Doctoral Dissertation, Purdue University.

Dantzich, M.v., et al., 2002. Scope: providing awareness of multiple notifications at a glance. In: Proceedings of the 6th international working conference on advanced visual interfaces, Trento, Italy. ACM, 267-281.

Ding, Y., Guo, C., and Wang, H., 2005. Design and implementation of real-time notification service. Jisuanji Gongcheng/Computer Engineering, 31 (5), 93-95.

Efendioglu, A.M. and Yip, V.F., 2004. Chinese culture and e-commerce: an exploratory study. Interacting with Computers, 16 (1), 45-62.

Fern, E.F., 2001. Advanced focus group research. Thousand Oaks, CA: Sage Publications.

Ferraro, G., 1994. The culture dimension of international business, 2nd ed. Englewood Cliffs, NJ: Prentice-Hall.

Fogarty, J., et al., 2005b. Predicting human interruptibility with sensors. ACM Transactions on Computer Human Interaction, 12 (1), 119-146.

Fogarty, J., et al., 2005a. Examining task engagement in sensor-based statistical models of human interruptibility. In: Proceedings of the CHI '05 conference on human factors in computing systems. New York: ACM, 331-340.

Fukuyama, F., 1995. Trust: the social virtues and the creation of prosperity. New York: Free Press.

Galletta, D., et al., 2006. Understanding the direct and interaction effects of web delay and related factors: a research program. In: D. Galletta and P. Zhang, eds. Human-computer interaction and management information systems: applications. New York: M.E Sharp, 29-69.

Gould, E.W., 2001. More than content: web graphics, crosscultural requirements, and a visual grammar. In: Proceedings of the 9th international conference on human-computer interaction, Mahwah, NJ, 506-509.

Hall, E.T., 1983. Dance of life: the other dimension of time. ME: Intercultural Press.

Hall, E.T., 1987. Beyond culture. New York: Doubleday.
Hall, E.T., 1990. Understanding cultural differences. ME: Intercultural Press.

Hampden-Turner, C. and Trompenaars, F., 1994. The seven cultures of capitalism. London: Piatkus.

Heary, C.M. and Hennessy, E., 2002. The use of focus group interviews in pediatric health care research. Journal of Pediatric Psychology, 27 (1), 47-57.

Hofstede, G., 1991. Cultures and organizations: software of the mind. New York: McGraw-Hill.

Hsieh, G. and Mankoff, J., 2003. A comparison of two peripheral displays for monitoring email: usability, awareness, and distraction. Tech Report UCB//CSD-03-1286, U.C.

Huang, D.L., et al., 2007. Effects of time orientation on design of notification systems. In: Proceedings of the $12^{t h}$ international conference on human-computer interaction, interaction design and usability. Beijing. Springer, 835-843.

Iqbal, S.T. and Bailey, B.P., 2008. Effects of intelligent notification management on users and their tasks. In: Proceedings of the ACM conference on human factors in computing systems. New York: ACM, 93-102.

Kim, D., Pan, Y., and Park, H.S., 1998. High- versus lowcontext culture: a comparison of Chinese, Korean, and American cultures. Psychology and Marketing, 15 (6), 507-521.

Kress, G. and van Leeuwen, T., 1996. Reading images: the grammar of visual design. London: Rutledge.

Krueger, R.A. and Casey, M.A., 2000. Focus groups - a practical guide for applied research, 3rd ed. Thousands Oaks: Sage Publications.

Lessem, R. and Neubauer, F., 1994. European management system. London: McGraw-Hill.

Mamaghani, F., 2002. Evaluation and selection of an antivirus and content filtering software. Information Management and Computer Security, 10 (1), 28-32.

Mankoff, J., et al., 2003. Heuristic evaluation of ambient displays. In: Proceedings of the SIGCHI conference on Human factors in computing systems, Ft Lauderdale Florida, USA. ACM, 169-176.

McCrickard, D.S., 1999. Maintaining information awareness with Irwin. In: Proceedings of the world conference on educational multimedia/hypermedia and educational telecommunications (ED-MEDIA '99), Seattle, WA, ACM.

McCrickard, D.S. and Chewar, C.M., 2003. Attuning notification design to user goals and attention costs. Communications of the ACM, 46 (3), 67.

McCrickard, D.S., et al., 2003. A model for notification systems evaluation - assessing user goals for multitasking activity. ACM Transactions on Computer-Human Interaction, 10 (4), 312-338.

McCrickard, D.S., Czerwinski, M., and Bartram, L., 2003. Introduction: design and evaluation of notification user interfaces. International Journal of Human-Computer Studies, 58 (5), 509-514.

Payne, B.D. and Edwards, W.K., 2008. A brief introduction to usable security. IEEE Internet Computing, 12 (3), $13-21$.

Plocher, T., et al., 2001. Understanding the Chinese user: attitudes toward automation, work, and life. In: M. Smith and G. Salvendy, eds. Systems, social, and internationalization design aspects of human-computer interaction. New Jersey: Lawrence Erlbaum Associates, 524-528.

Post, G. and Kagan, A., 1998. Use and effectiveness of antivirus software. Computers and Security, 17 (7), 589-599. 
Prabhu, G. and Harel, D., 1999. CUI design preference validation for Japan and China - a case for KANSEI engineering. In: Proceedings of the 8 th international conference on human-computer interaction (HCI99), Munich, Germany, 521-525.

Rau, P.-L.P. and Liang, S.-F.M., 2003. A study of cultural effects of designing a user interface for a web-based service. International Journal of Services Technology and Management, 4 (4/5/6), 480-493.

Rose, G.M., Evaristo, R., and Straub, D., 2003. Culture and consumer responses to web download time: a fourcontinent study of mono and polychronism. IEEE Transactions on Engineering Management, 50 (1), 31-44.

Smith, A., et al., 2004. A process model for developing usable cross-cultural websites. Interacting with Computers, 16 (1), 63-91.

Stoll, J., et al., 2008. Sesame: informing user security decisions with system visualization. In: Proceedings of the ACM conference on human factors in computing systems (CHI 2008), 5-10 April, Florence, Italy. ACM, 1045-1054.

Terpstra, V. and David, K., 1985. The cultural environment of international business, 2nd ed. Cincinnati: South-Western Publishing.

TopTenREVIEWS, 2007. Anti-virus software reviews 2007 [online]. Available from: http://anti-virus-softwarereview.toptenreviews.com [Accessed 10 March 2007].

Trafton, J.G., et al., 2003. Preparing to resume an interrupted task: effects of prospective goal encoding and retrospective rehearsal. International Journal of Human Computer Studies, 58 (5), 583.

Trompenaars, F. and Hampden-Turner, C., 1997. Riding the waves of culture: understanding cultural diversity in business. London: Nicholas Brealey Publishing.

Zhang, L., Tu, N., and Vronay, D., 2005. Info-Lotus: a peripheral visualization for email notification. In: $\mathrm{CHI}$ '05 extended abstracts on human factors in computing systems. Portland, OR, USA, 1901-1904.

\section{Appendix. Notification messages used in the experiment}

There were 26 messages, and each message was displayed for $5 \mathrm{~s}$. The intervals between messages were random times within a range of 1 to $10 \mathrm{~s}$. All the messages were displayed in Chinese in the experiment. The names of the four team members were Yao Ming, Liu Xiang, Liu Dehua and Zhao Wei. The team members were assigned the names of these celebrities because users were familiar with them and could easily recall them. All locations mentioned in the messages were famous places in Beijing and should be known by the participants.

Manager: Our project team is going out to have fun on the weekend. Does anyone have a suggestion what to do, where to go, and when we should meet?

Liu Dehua: I suggest singing karaoke.

Yao Ming: The weather is good; let's go mountain climbing. Zhao Wei: I would also like to go to the mountains.

Liu Xiang: Both suggestions are fine with me.

Liu Dehua: But we have not gone to a karaoke bar for quite a long time.

Zhao Wei: I don't like singing.

Yao Ming: My singing is really terrible.

Liu Dehua: Alright, then. I also agree with the mountain climbing suggestion.

Manager: OK. So which mountain are we going to climb?

Yao Ming: Let's go to the Fragrant Hills. We'll be able to

Zhao Wei: Great!

Liu Dehua: There are too many people at Fragrant Hills these days. We could go to Yunmeng Mountain. There are also maples there, and fewer people.

Liu Xiang: I agree. Yunmeng Mountain is not very far from here.

Zhao Wei: That also sounds good.

Manager: OK, so we will go to climb Yunmeng Mountain this Saturday. Is that OK for everyone?

Yao Ming: OK.

Zhao Wei: OK.

Liu Dehua: OK.

Liu Xiang: It's OK with me. I think we'd better get going in the morning.

Manager: OK, so we will meet in the office at 9:00 on Saturday morning, and then go to Yunmeng Mountain.

Yao Ming: OK.

Zhao Wei: OK.

Liu Dehua: OK.

Liu Xiang: OK.

Manager: Good, so see you on Saturday. Don't forget to wear sturdy shoes and bring something to drink. 